\title{
Long-term fluoxetine treatment induces input-specific LTP and LTD impairment and structural plasticity in the CA1 hippocampal subfield
}

\author{
Francisco J. Rubio ${ }^{1+}{ }^{\text {, Estíbaliz Ampuero }}{ }^{1+}$, Rodrigo Sandoval ${ }^{2}$, Jorge Toledo ${ }^{1}$, Floria Pancetti ${ }^{2}$ and \\ Ursula Wyneken ${ }^{1 *}$
}

${ }^{1}$ Laboratorio de Neurociencias, Centro de Investigaciones Biológicas, Universidad de los Andes, Santiago, Chile

${ }^{2}$ Laboratorio de Neurotoxicologia Ambiental, Universidad Católica del Norte, Coquimbo, Chile

\section{Edited by:}

Rena Li, Roskamp Institute, USA

Reviewed by:

Maarten H. P. Kole, Netherlands

Institute for Neuroscience,

Netherlands

Rif S. El-Mallakh, University of

Louisville School of Medicine, USA

*Correspondence:

Ursula Wyneken, Laboratorio de

Neurociencias, Centro de

Investigaciones Biológicas,

Universidad de los Andes, San

Carlos de Apoquindo, 2200

Las Condes 762001, Santiago, Chile.

e-mail:uwyneken@uandes.cl

tThese authors have contributed

equally to this work.
Antidepressant drugs are usually administered for several weeks for the treatment of major depressive disorder. However, they are also prescribed in several additional psychiatric conditions as well as during long-term maintenance treatments. Antidepressants induce adaptive changes in several forebrain structures which include modifications at glutamatergic synapses. We recently found that repetitive administration of the selective serotonin reuptake inhibitor (SSRI) fluoxetine to naïve adult male rats induced an increase of mature, mushroom-type dendritic spines in several forebrain regions. This was associated with an increase of GluA2-containing $\alpha$-amino-3-hydroxy-5-methylisoxazole-4-propionate receptors (AMPA-Rs) in telencephalic postsynaptic densities. To unravel the functional significance of such a synaptic re-arrangement, we focused on glutamate neurotransmission in the hippocampus. We evaluated the effect of four weeks of $0.7 \mathrm{mg} / \mathrm{kg}$ fluoxetine on long-term potentiation (LTP) and long-term depression (LTD) in the CA1 hippocampal subfield. Recordings in hippocampal slices revealed profound deficits in LTP and LTD at Schaffer collateral-CA1 synapses associated to increased spine density and enhanced presence of mushroomtype spines, as revealed by Golgi staining. However, the same treatment had neither an effect on spine morphology, nor on LTP and LTD at perforant path-CA1 synapses. Cobalt staining and immunohistochemical experiments revealed decreased AMPA-R Ca ${ }^{2+}$ permeability in the stratum radiatum (s.r.) together with increased GluA2-containing $\mathrm{Ca}^{2+}$ impermeable AMPA-Rs. Therefore, 4 weeks of fluoxetine treatment promoted structural and functional adaptations in CA1 neurons in a pathway-specific manner that were selectively associated with impairment of activity-dependent plasticity at Schaffer collateral-CA1 synapses.

Keywords: antidepressants, LTP, LTD, dendritic spines, glutamate receptors

\section{INTRODUCTION}

Fluoxetine is a selective serotonin reuptake inhibitor (SSRI) that is widely used to treat anxiety- and mood-related disorders, but in addition, its use has been expanded to other psychiatric conditions and is often continued after remission of symptoms (Schatzberg, 2000; Blier et al., 2007). The therapeutic effect of antidepressant drugs is mediated by cellular events which include adult hippocampal neurogenesis, maturation of nascent neurons and changes in gene expression. It has been shown that the activation of gene transcription following fluoxetine treatment is elicited by epigenetic remodeling of chromatin structure leading to increased plasticity and dendritic spine remodeling (Maya Vetencourt et al., 2011; Wang et al., 2011). This has been proposed to underlie plastic changes in glutamate neurotransmission (Pittenger and Duman, 2008; Sanacora et al., 2008; Maya-Vetencourt et al., 2012).

It had been previously described by us that 28 days of $0.7 \mathrm{mg} / \mathrm{kg}$ fluoxetine administration to adult naïve rats induced growth of dendritic spines and changes in glutamate receptor subunit composition in cerebrocortical synapses (Ampuero et al., 2010). In addition, such changes led to impairment of remote, but not recent, hippocampus-dependent memory (Ampuero et al., 2013). To study the effect of fluoxetine on cellular plasticity, we focused on CA1 pyramidal neurons which receive spatially segregated direct and indirect excitatory inputs from the entorhinal cortex (EC) via the perforant path and the Schaffer collaterals originating in CA3, respectively. While Schaffer collaterals terminate in the CA1 stratum radiatum (s.r.) on proximal dendrites, the direct perforant path makes synapses on the distal dendrites of CA1 neurons that are localized in the stratum lacunosum moleculare (s.l.m.) (Steward, 1976).

The induction of long-term potentiation (LTP) and long-term depression (LTD) of excitatory synaptic transmission at CA1 requires both $\mathrm{N}$-methyl-D-aspartate receptor (NMDA-R) activation and trafficking of $\alpha$-amino-3-hydroxy-5-methylisoxazole4-propionate receptors (AMPA-Rs) (Citri and Malenka, 2008). 
NMDA-Rs are heterotetramers composed mandatorily of two GluN1 and two GluN2 subunit types (A to D), whereas AMPARs are comprised of four unique subunits, GluA1-GluA4. In the adult hippocampus, AMPA-Rs are heterotetramers assembled preferentially by GluA1 and GluA2/GluA3 subunits. Subunit composition is a major determinant of biophysical channel properties, downstream signaling, receptor trafficking and synaptic plasticity. In such a way, GluA2-containing receptors are $\mathrm{Ca}^{2+}$ impermeable, in contrast to GluA2-lacking channels that are permeable to the divalent ion (Traynelis et al., 2010). High frequency synaptic stimulation induces LTP via NMDA-R-dependent $\mathrm{Ca}^{2+}$ influx, activation of several protein kinases and recruitment of GluA1-containing AMPA-Rs to the synapse. In contrast, LTD is induced by low frequency synaptic stimulation, prolonged increases in calcium levels leading to protein phosphatase activation and GluA1- and GluA2-containing AMPA-R internalization (Derkach et al., 2007; Isaac et al., 2007; Citri and Malenka, 2008). Although the contribution of specific AMPA$\mathrm{R}$ subunits is not firmly established for LTD, GluA1 subunits at least play an important role (Meng et al., 2003; He et al., 2011). Additionally, LTP and LTD are accompanied by opposing changes in spine density and morphology, i.e., spine length, head volume, and neck diameter. As such, LTP correlates with growth of new spines and enlargement of preexisting spines whereas LTD associates with shrinkage and loss of spines (Segal, 2005).

Based on the fluoxetine-induced enrichment of GluN2A over GluN2B-containing NMDA-Rs and GluA2 over GluA1containing AMPA-Rs (Ampuero et al., 2010) associated to increased mushroom-type spines, we hypothesized that such changes might negatively affect further potentiation. Therefore, we examined the consequences of repetitive fluoxetine treatment on spine morphology as well as LTP and LTD in the proximal and distal dendrites within the CA1 s.r. and s.l.m., respectively. Our data indicated that fluoxetine did not induce structural nor functional changes at perforant path-CA1 synapses. However, consistent with our hypothesis, increased mushroom-type dendritic spines on proximal dendrites, where Schaffer collateral to CA1 synapses occur in the s.r. were associated with a significant reduction of LTP. Interestingly, LTD was also impaired at these synapses. In addition, AMPA-R-dependent $\mathrm{Ca}^{2+}$ permeability was decreased specifically in the s.r. along with increased GluA2 content in AMPA-Rs.

\section{MATERIALS AND METHODS ANIMALS}

Adult male Sprague-Dawley rats weighting $280-300 \mathrm{~g} \quad(\sim 12$ weeks old) at the beginning of the fluoxetine treatment were used for all experiments. All procedures involving animals were approved by the Universidad de los Andes Bioethical Committee and were performed in accordance with the National Institute of Health Guide for the Care and Use of Laboratory Animals (NIH Publications No. 80-23). Either saline ( $0.9 \% \mathrm{NaCl}$, control group) or $0.7 \mathrm{mg} / \mathrm{kg}$ fluoxetine (Ely-Lilly Co., Indianapolis, USA) dissolved in saline was administered daily via i.p. injection between 9:00 and 10:00 AM for 28 days (flx 4 weeks). A second control group of rats received a single fluoxetine injection (flx $24 \mathrm{~h}$ ).
In total, 85 rats were sacrificed $24 \mathrm{~h}$ following the last fluoxetine or saline injection to perform electrophysiological recordings $(n=39)$, Golgi staining $(n=17)$, immunohistochemistry $(n=12)$, and cobalt staining $(n=17)$. For immunohistochemistry or for Golgi staining, rats were sacrificed under ketamine $(50 \mathrm{mg} / \mathrm{kg})$ and xylazine $(10 \mathrm{mg} / \mathrm{kg})$ anesthesia and then perfused intracardially with saline followed by $300 \mathrm{ml}$ of $4 \%$ paraformaldehyde in PBS.

\section{EXTRACELLULAR FIELD RECORDINGS IN THE CA1 HIPPOCAMPAL SUBFIELD}

Recordings were performed in hippocampal slices, as previously reported (Olmos et al., 2009). In each experimental group, 2-3 slices per rat were recorded. The animals were anesthetized with halothane gas and then intracardially perfused with artificial cerebrospinal fluid (aCSF, in mM; $124 \mathrm{NaCl} ; 5 \mathrm{KCl} ; 1.25 \mathrm{NaH}_{2} \mathrm{PO}_{4}$; $1.0 \mathrm{MgCl}_{2} ; 2.0 \mathrm{CaCl}_{2} ; 26 \mathrm{NaHCO}_{3} ; 10$ glucose; $\left.\mathrm{pH} 7.4\right)$. After perfusion, the animals were decapitated and brains rapidly removed, immersed in ice-cold dissection buffer (in $\mathrm{mM} ; 212.7$ sucrose; $5 \mathrm{KCl} ; 1.25 \mathrm{NaH}_{2} \mathrm{PO}_{4} ; 3 \mathrm{MgSO}_{4} ; 1 \mathrm{CaCl}_{2} ; 26 \mathrm{NaHCO}_{3} ; 10$ glucose; $\mathrm{pH}$ 7.4) and then the hippocampi dissected to obtain transverse slices ( $400 \mu \mathrm{m}$ thickness) with a vibratome (Campden Instruments, Leicester, UK). Slices were transferred to an interface chamber containing aCSF saturated with $95 \% \mathrm{O}_{2} / 5 \% \mathrm{CO}_{2}$ at $36^{\circ} \mathrm{C}$, left at these conditions for $45 \mathrm{~min}$, and then maintained at $24^{\circ} \mathrm{C}$ for $1 \mathrm{~h}$. Single slices were transferred to a recording chamber containing aCSF and continually perfused at a flow of $2 \mathrm{ml} / \mathrm{min}$.

Recording electrodes were glass micropipettes (1-3 M $\Omega$ ) filled with aCSF. For CA3-CA1 experiments, the concentric bipolar stimulating electrode (FHC Corporate and Manufacturing, Bowdoin, ME, USA) was placed on the Schaffer collateral fibers, and the recording electrode into the s.r. of the CA1 region. For input-output (I/O) experiments, increasing current steps from 0 to $500 \mu \mathrm{A}$ were applied. Averaged fiber volley amplitude vs. fEPSP slope was plotted. For LTP experiments, stimuli able to elicit 50\% of the maximum fEPSP response were used for baseline recordings and theta burst stimulation (TBS). LTP was elicited after $20 \mathrm{~min}$ of a stable baseline using electrical stimulation (constant current, $200 \mu \mathrm{s}$ stimuli) delivered every $15 \mathrm{~s}$. The TBS protocol consisted of five stimuli trains with an inter-train interval of $10 \mathrm{~s}$. Each train consisted of 10 bursts at $5 \mathrm{~Hz}$, each burst having four pulses at $100 \mathrm{~Hz}$. After TBS, potentiation was recorded for $1 \mathrm{~h}$. For LTD experiments, the stimulus intensity was adjusted to elicit $80 \%$ of the maximum response for baseline recordings and low frequency stimulation (LFS). LTD was elicited after $20 \mathrm{~min}$ of a stable baseline using electrical stimulation (constant current, $200 \mu$ s stimuli) delivered every $30 \mathrm{~s}$. The LFS protocol to induce LTD consisted of 1200 pulses at $2 \mathrm{~Hz}$ and thereafter, data acquisition lasted $60 \mathrm{~min}$. To test the plasticity of the direct pathway from the EC to CA1 synapses, the stimulation electrode was placed on the temporoammonic pathway while recordings were performed in the s.l.m. of the CA1 hippocampal area using the same stimulation protocol as in Schaffer collateral-CA1 s.r. recordings (Remondes and Schuman, 2002), but in this case the aCSF contained $4.0 \mathrm{mM} \mathrm{CaCl}_{2}$. Hippocampal slices were mechanically de-afferented from Schaffer collaterals. 
Voltage recordings were acquired using an extracellular amplifier (Dagan Corporation, Minneapolis, MI, USA) and a data acquisition board (National Instruments, USA) controlled through Igor Pro software (Wavemetrics Inc., USA). LTP and LTD plots were obtained by measuring the fEPSP slopes, considering the baseline as $100 \%$.

\section{SPINE DENSITY AND MORPHOLOGY}

Brains were processed using the FD Rapid GolgiStainTM kit (FD Neuro Technologies, Baltimore, USA) and analyzed as already described (Ampuero et al., 2007, 2010). Briefly, 11 selected pyramidal neurons of hippocampal layer CA1 were examined per experimental condition. Proximal secondary dendrites in the s.r. that emerged from the primary dendrite at $<50 \mu \mathrm{m}$ away from the soma were examined. Distal dendrites were at $>150 \mu \mathrm{m}$ away from the soma and corresponded to s.l.m. dendrites. It is known that histological techniques lead to shrinkage due to fixation, processing, dehydration, and mounting of samples. In our case, the dentate gyrus was clearly visible at about $380 \mu \mathrm{m}$ away from the pyramidal cell layer, indicating that at stretches between 200 and $350 \mu \mathrm{m}$ we are positioned in the s.l.m. In two cases, based on a second criterion used to select s.l.m. dendrites: i.e., that s.r. pyramidal cell dendrites run perpendicular to the hippocampal fissure while this perpendicular orientation is absent in s.l.m. (Pyapali et al., 1998; Megias et al., 2001), selected dendrite stretches began at $\sim 160 \mu \mathrm{m}$ away from the cell body. Spines were quantified along segments of $50 \mu \mathrm{m}$. Spine density was calculated as number of spines per $\mu \mathrm{m}$ and spine shape classification was performed under the microscope at different focal planes into three groups: (1) filopodia/thin, (2) stubby and (3) mushroom/branched. In a few cases (less than 10\%) in which spine category was not clear to the observer, spine, and neck diameters were measured at the focal plane in which the image appeared at its maximal size and classified according to measures reported by Harris (Harris et al., 1992). Photomicrographs for representative images were captured with a ZeissAxioplan 2 microscope $(100 \times$ objective, numerical aperture 1.3) attached to a Nikon COOLPIX995 digital camera (final magnification of $4700 \times$ ).

\section{IMMUNOSTAINING}

Anti-GluA1 (1:50) and anti-GluA2 (1:400) from Millipore (Temecula, CA, USA) for immunofluorescence and immunohistochemical staining were used. For immunofluorescence, the secondary antibody Alexa Fluor ${ }^{\circledR} 488$ conjugated to goat antirabbit IgG (1:400) from Invitrogen (Eugene, OR, USA) was used. Fluorescent images were obtained on a confocal microscope (LSM 510 Meta, Zeiss, USA; 20× magnification) using LSM 5 Pascal software. For immunohistochemistry, primary antibodies were detected with biotinylated anti-rabbit secondary antibody (1:200, Jackson ImmunoResearch Laboratories, Inc., West Grove, PA, USA) and 3,3-diaminobenzidine tetrahydrochloride (DAB) using a nickel-intensified reaction according to the published protocol (Ampuero et al., 2010). For quantification of immunochemical staining, brain slices were visualized under a light microscope (AxiosKop, Zeiss, Germany; 10× magnification; numeric aperture 0.3), and images of serial sections were captured with a digital camera (Nikon, CoolPIX 995) with a final magnification of $37 \times$.
Digitized images were analyzed with the NIH ImageJ software. Optical density of hippocampal s.r., s.l.m., and stratum pyramidale (s.p.) layers in CA1 was analyzed from 3 to 5 sections per animal restricted to bregma $-3.14 \mathrm{~mm}$ and bregma $-4.52 \mathrm{~mm}$ and five consecutive areas of $47.3 \pm 1.6 \mu \mathrm{m}^{2}$ were quantified. In the case of the s.l.m., these areas were selected at 30-80 $\mu \mathrm{m}$ away from the hippocampal fissure, perpendicular toward the s.p. cell layer.

\section{COBALT STAINING}

The $\mathrm{Ca}^{2+}$ permeability of GluA1-containing AMPARs was evaluated in fresh hippocampal sections using a modified cobalt staining technique, adapted from Osswald et al. (2007). Briefly, three to five slices per animal ( $n=9$ animals per condition) were incubated with $5 \mathrm{mM} \mathrm{CoCl}_{2}$ in assay buffer for $10 \mathrm{~min}$ in presence of a NMDA-R antagonist $(40 \mu \mathrm{M}$ aminophosphonovalerate, APV), a voltage-dependent $\mathrm{Na}^{+}$channel blocker $(1 \mu \mathrm{M}$ tetrodotoxin), and a $\mathrm{Ca}^{2+}$ channel blocker ( $2 \mu \mathrm{M}$ Nimodipine). The AMPA- $\mathrm{R}$ antagonist, 6-cyano-7-nitroquinoxaline-2,3-dione ( $20 \mu \mathrm{M}$ CNQX), was added to negative controls. Sections were incubated with the AMPA-R agonist quiscualic acid $(100 \mu \mathrm{M})$ for $20 \mathrm{~min}$. Intracellular $\mathrm{Co}^{2+}$ was precipitated with $0.24 \%$ ammonium sulfide, and slices were fixed in $0.8 \%$ glutaraldehyde. Silver enhancement of the $\mathrm{Co}^{2+}$ sulfide precipitate was obtained with $\mathrm{AgNO}_{3}$. Photomicrographs of hippocampal sections were captured with a stereoscopic microscope attached to a Nikon COOLPIX995 digital camera at a final magnification of $3.74 \times$. For each hippocampal digital image, the dorsal-most CA1 subfield was selected and the mean optical density of $114.0 \times$ $28.5 \mu \mathrm{m}\left(3250 \mu \mathrm{m}^{2}\right)$ rectangles was calculated for each layer, i.e., s.p., s.l.m., and s.r., and using NIH ImageJ software.

\section{STATISTICAL ANALYSIS}

The GraphPad PRISM 4.0 software was used to analyze data. Data are presented as mean \pm SEM. For morphological and optical density analysis, the Mann-Whitney $U$-test was applied. In the electrophysiological experiments $n$-value represents the mean of 2-3 slices per rat per condition. For input/output curves, data from each experimental group was fit to a linear regression and compared using covariate analysis. LTP and LTD data was subjected to one-way analysis of variance (ANOVA), followed by a Bonferroni post-hoc test.

\section{RESULTS}

\section{FLUOXETINE INDUCED CHANGES IN SPINE DENSITY AND MUSHROOM-TYPE MORPHOLOGY IN THE CA1 s.r., BUT NOT IN THE s.I.m.}

In order to examine the morphology of the post-synaptic compartment in CA1, i.e., dendritic spines, the Golgi staining method was used. Spine morphology and spine density of secondary dendrites was analyzed at proximal segments emerging $<50 \mu \mathrm{m}$ away from the soma of hippocampal CA1 neurons (Figure 1A). Spine density (spines $/ \mu \mathrm{m}$ ) increased significantly from $1.59 \pm 0.11$ to $1.92 \pm 0.07$ after 4 weeks of fluoxetine treatment $(p<0.05)$. This increase was accompanied by a higher proportion of mushroomtype spines (saline: $26.2 \pm 1.7 \%$; fluoxetine: $39.6 \pm 1.8 \%, p<$ 0.001 ) and a concomitant decrease of thin (saline: $30.7 \pm 1.4 \%$; 


\section{A}

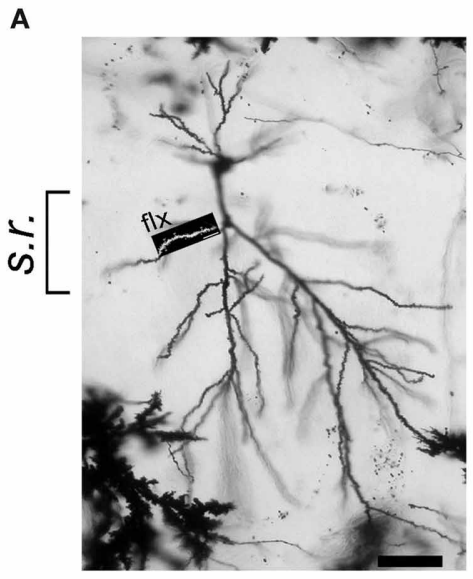

\section{sal}

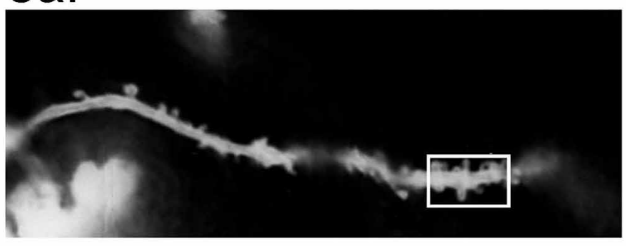

flx

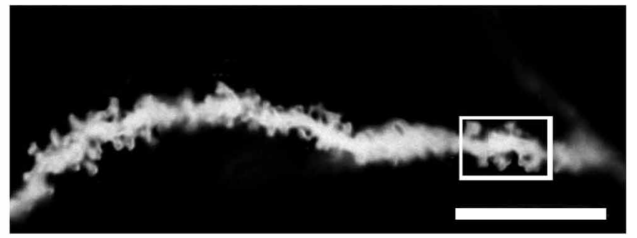

B

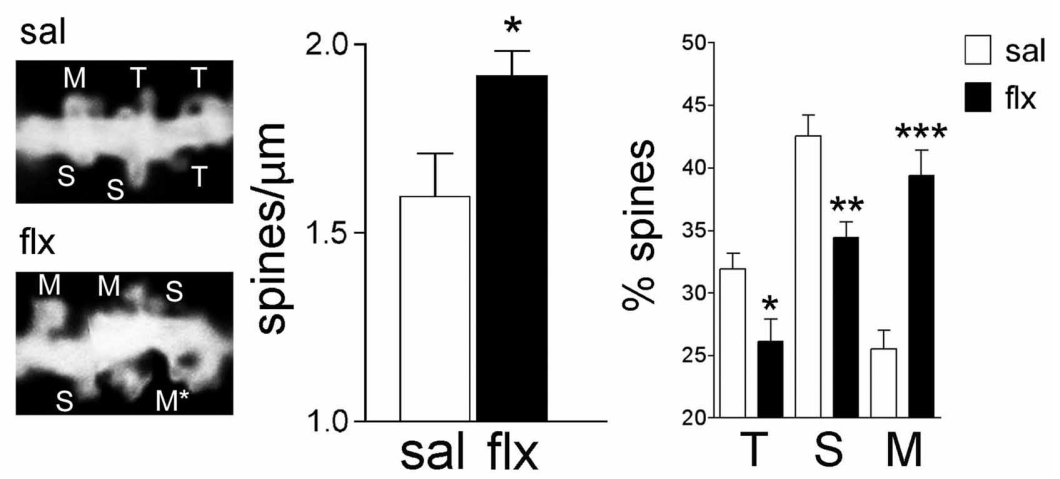

FIGURE 1 | Long-term fluoxetine treatment induces morphological changes in proximal dendritic spines of CA1 pyramidal neurons. (A) Left: A representative image of a Golgi stained neuron from a fluoxetine-treated rat. CA1 stratum radiatum (s.r.) subfield was chosen for analysis. Scale bar: $50 \mu \mathrm{m}$. Right: representative dendritic segments of saline and fluoxetine-treated rats under larger amplification. Scale bar: $10 \mu \mathrm{m}$. (B) The selected dendritic segments in (A) (right panels) are shown with identified spine types: filopodia/thin (T), stubby (S), and mushroom/branched (M). The asterisks indicate two superimposed M-type spines that were resolved by observation at different focal planes. Bar graphs show spine density and the abundance of spines in each of the three shape categories. Results are presented as mean \pm SEM and were determined from 11 cells per condition, obtained from eight saline (total spines, 874)- and nine fluoxetine (total spines, 957)-treated rats. Data were statistically evaluated with the Mann-Whitney $U$-test, ${ }^{*} p<0.05$, ${ }^{* *} p<0.01,{ }^{* * *} p<0.001$. fluoxetine: $26.1 \pm 1.4 \% ; p<0.05)$ and stubby spines (saline: $43.1 \pm 2.3 \%$; fluoxetine: $34.3 \pm 1.1 \% ; p<0.01$ ) (Figure 1B). These observations indicated that repetitive fluoxetine administration induced synaptogenesis and synapse maturation in the hippocampal CA1 s.r., similarly to those reported in some cerebrocortical regions (Ampuero et al., 2010). To test whether changes in spine morphology extended to distal dendrites, spine density and shape were quantified on secondary dendrites emerging at distances farther than $150 \mu \mathrm{m}$ away from the cell soma, located in the s.l.m. (Figure 2A). In contrast to the previous findings, no change in spine density nor in the proportion of morphological sub-types were found within the CA1 s.l.m. subfield (Figure 2B).

\section{LONG-TERM FLUOXETINE TREATMENT INCREASED EXCITABILITY AT SCHAFFER COLLATERAL-CA1 SYNAPSES, BUT IMPAIRED LTP AND LTD}

To compare the effect of repetitive fluoxetine on basal neurotransmission and activity-dependent synaptic plasticity at CA3-CA1 synapses, we compared treated animals to two control groups: saline-treated rats and rats exposed to a single fluoxetine injection. Therefore, a direct effect of fluoxetine could be discarded. Stimulus-evoked fEPSPs were recorded at the CA1 s.r. after Schaffer collateral stimulation (Figure 3A). First, post-synaptic excitability was tested by I/O curves, in which the fEPSP slopes were measured in response to single electrical stimuli of increasing magnitude. Significantly higher fEPSP slopes were recorded after 28 days of fluoxetine treatment, as compared to both control groups (Figure 3B).

Application of the TBS protocol, which is capable of inducing robust LTP in saline-treated animals, was not able to induce LTP nor LTD in rats chronically treated with fluoxetine. In Figure 3C, representative recordings are shown. The mean \% of fEPSP slopes, ranging from 45 to $60 \mathrm{~min}$ after the TBS, were pooled for analysis (saline: $161.3 \pm 10.8 \%$; fluoxetine $24 \mathrm{~h}: 147.7 \pm 6.7 \%$; fluoxetine 4 weeks: $110.7 \pm 2.4 \% ; F_{(2,14)}=16.04, p<0.001$; Figure 3D). A single fluoxetine injection did not interfere with 


\section{A}

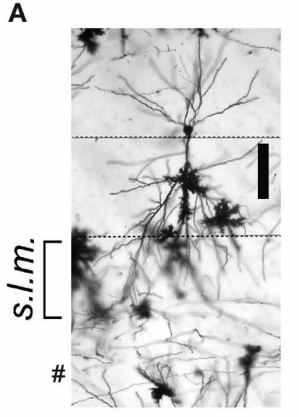

B

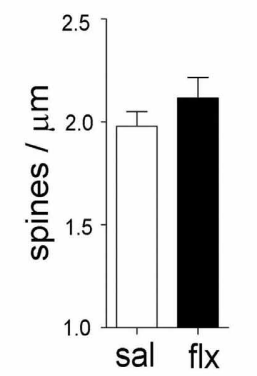

\section{sal}
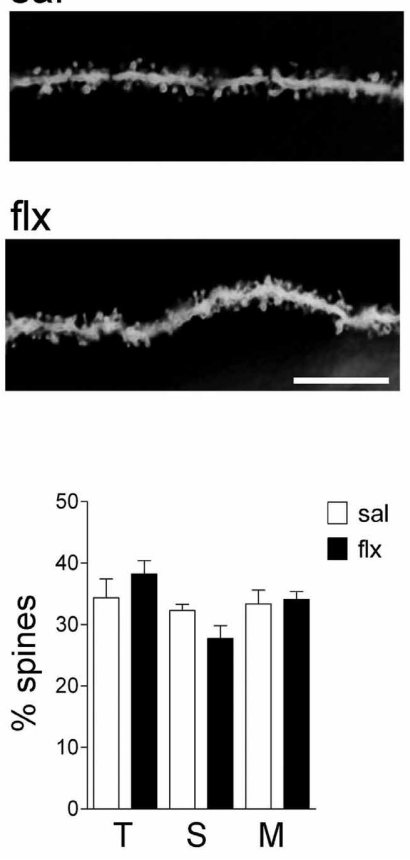

FIGURE 2 | Long-term fluoxetine treatment does not affect distal dendritic spine morphology of CA1 pyramidal neurons. (A) Left: Golgi stained CA1 pyramidal neuron indicating the stratum lacunosum moleculare (s.l.m.) where the morphological analysis was performed. \#At this level can be observed granule neuron dendrites coming from dentate gyrus. Scale bar: $100 \mu \mathrm{m}$. Right: representative dendritic segments of saline and fluoxetine-treated rats under larger amplification. Scale bar: $10 \mu \mathrm{m}$. (B) The number of spines and the morphology of spines were analyzed and plotted as spine density and \% of spine type, respectively. Filopodia/thin (T), stubby (S), and mushroom/branched (M) shape categories are shown. Results are presented as mean \pm SEM and were determined from 10 to 11 cells per condition, obtained from five saline (total spines, 979)- and six fluoxetine (total spines, 942)-treated rats. Data were not statistically significant after a Mann-Whitney $U$-test analysis.

LTP induction. A similar analysis of the LTD data revealed that LTD was blocked after repetitive fluoxetine treatment, but not after a single fluoxetine dose (saline: $77.5 \pm 2.4 \%$; fluoxetine $24 \mathrm{~h}$ : $71.0 \pm 3.7 \%$; fluoxetine 4 weeks: $101.3 \pm 1.0 \%, F_{(2,11)}=46.23$, $p<0.0001$; Figure 3E). These results revealed that long-term fluoxetine, able to induce morphological changes in the postsynaptic compartment, induced deficits in activity-dependent plasticity. In turn, the increased excitability observed at CA3-CA1 synapses can be due to increased spine density and/or the fact that large spines are known to generate a larger postsynaptic responses (Spruston, 2008).

To further clarify whether the detrimental effects of fluoxetine on LTP and LTD were associated with the changes in spine morphology and density, electrophysiological recordings at perforant path-CA1 synapses were performed.

\section{LONG-TERM FLUOXETINE TREATMENT DID NOT AFFECT LTP NOR LTD AT PERFORANT PATH-CA1 SYNAPSES}

Stimulus-evoked fEPSPs were recorded at the CA1 s.l.m. after temporoammonic pathway stimulation (Figure 4A). No significant differences in fEPSP slopes were observed between saline- and fluoxetine-treated rats after 28 days of administration (saline: $0.3773 \pm 0.1753$; fluoxetine 4 weeks: $0.3838 \pm$ $0.1335, p=0.997$; Figure 4B). LTP or LTD were induced in these synapses after TBS or LFS stimulation, respectively, in slices from saline- and repetitively fluoxetine-treated rats. In Figures 4C and $\mathrm{D}$, representative recordings are shown. The mean \% of fEPSP slopes, ranging from 45 to $60 \mathrm{~min}$, indicated that both groups had similar LTP and LTD responses (LTP, saline: $166 \pm 8.2 \%$; fluoxetine 4 weeks: $136 \pm 11.6 \%, p=0.143$; LTD, saline: $64.5 \pm$ $6.8 \%$; fluoxetine 4 weeks: $59 \pm 4.6 \%, p=0.519$; Figures $4 \mathrm{E}$ and F). As mushroom-type spines are enriched in $\mathrm{Ca}^{2+}$ impermeable GluA2-containing AMPA-Rs and as such, should contribute to limited plasticity observed in the CA1 s.r., where changes in spine morphology had been detected along with LTP and LTD impairment (Isaac et al., 2007; Medvedev et al., 2008).

\section{LONG-TERM FLUOXETINE TREATMENT INCREASED GIuA2-CONTAINING AMPA-Rs IN THE CA1 s.r. SUBFIELD}

Immunofluorescent labeling of GluA1 and GluA2 subunits was performed in brain sections after 4 weeks of either saline or fluoxetine administration. Confocal images revealed decreased GluA1, but enhanced GluA2 levels in the CA1 s.r. subfield following fluoxetine treatment (Figure 5A). To quantify the relative content of these subunits in hippocampal subfields, immunohistochemical staining was performed. The relative staining intensity compared to the s.p. in the s.r. and in the s.l.m. was assessed. While GluA1 staining did not change in neither of the subfields, increased GluA2 immunoreactivity was found in the s.r. of fluoxetinetreated rats (Figure 5B, $0.82 \pm 0.04$ vs. $1.01 \pm 0.05 ; p<0.05$ ). In contrast, no staining difference was found in the s.l.m. (not shown, $1.13 \pm 0.1$ vs. $1.14 \pm 0.08, n=5$ ). Interestingly, as already reported, these data revealed an increased AMPA-R subunit staining in the control situation in the s.l.m. when compared to the s.r. $(0.82 \pm 0.04$ vs. $1.13 \pm 0.1 ; p<0.05)$ (Nicholson et al., 2006) To further explore a higher GluA2 over GluA1 content at the functional level, the AMPA-R $\mathrm{Ca}^{2+}$-permeability was assessed by using the cobalt staining protocol (Figure 6). AMPA-Rs were stimulated with quisqualic acid while other $\mathrm{Ca}^{2+}$ influx pathways were pharmacologically blocked. After repetitive fluoxetine treatment, higher cobalt staining in the CA1 s.p. (saline: $100.3 \pm 6.2 \%$, fluoxetine: $169.9 \pm 8.9 \% ; p<0.001$ ) was found while the staining intensity in the CA1 s.r. (saline: $164.0 \pm 10.1 \%$, fluoxetine: $130.6 \pm 7.5 \% ; p<0.05)$ decreased. No differences were found among experimental groups in the s.l.m. (not shown, $168 \pm 16 \%$ vs. $163 \pm 17 \%$ ). All together, these results indicate that GluA2 is up-regulated in the s.r. while no staining differences could be detected in the s.l.m.

\section{DISCUSSION}

The main finding of the present work is that repetitive, but not a single, administration of low and clinically relevant doses of fluoxetine to naive rats enhanced the excitability of CA1 neurons, but impaired activity-dependent plasticity at hippocampal CA1 synapses in an input-specific manner. This impairment was associated to a selective increase of spine density and to a higher proportion of mushroom-type spines, restricted to the proximal dendritic segment of CA1 pyramidal cells that receives the Schaffer collateral input. At the molecular level, changes 
A

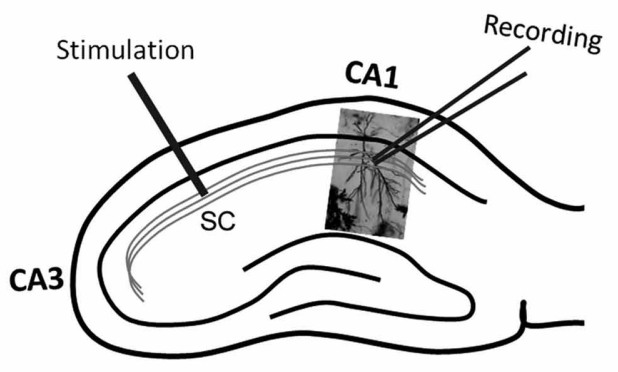

C

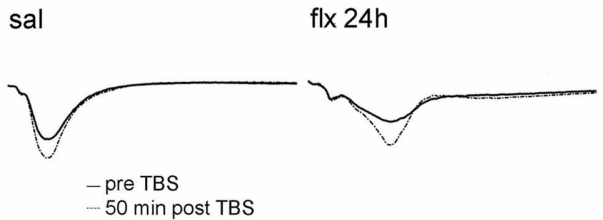

sal

flx $24 \mathrm{~h}$

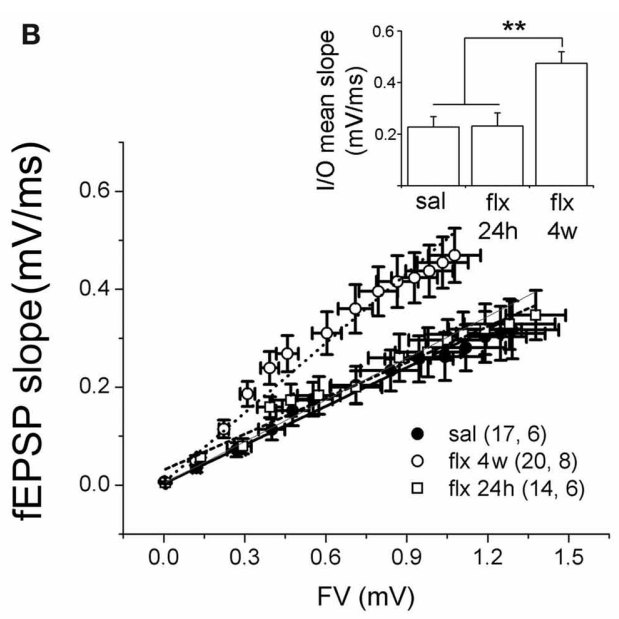

flx $4 \mathrm{w}$

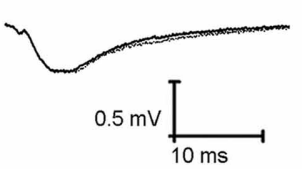

flx $4 \mathrm{w}$

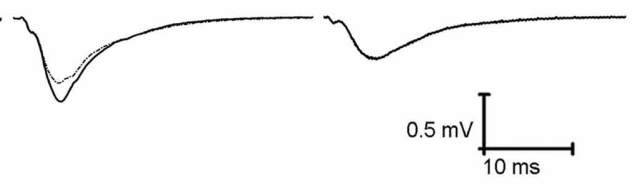

D

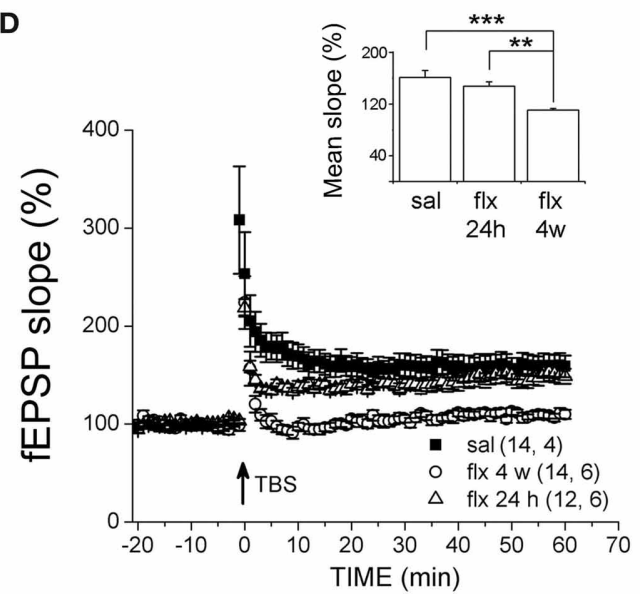

FIGURE 3 | Four weeks of fluoxetine administration affects basal synaptic transmission and synaptic plasticity at CA3-CA1 synapses. Experiments were performed in slices from saline (sal), single (flx $24 \mathrm{~h}$ ), and repeated (flx 4 weeks) fluoxetine treatment groups. (A) The diagram shows the stimulating electrode inserted into Schaffer collaterals (SC) and the recording electrode placed in the CA1 s.r. (B) Input/output curves. The fEPSP slopes vs. increasing presynaptic fiber volley (FV) amplitudes were plotted. Data were fit to a linear regression and compared using covariate analysis. The slope obtained in repetitive fluoxetine-treated rats $(0.48 \pm 0.05$, $\left.r^{2}=0.99\right)$ was significantly different $(p<0.01)$ compared to saline-treated rats $\left(0.23 \pm 0.04, r^{2}=0.99\right)$ or to rats treated with fluoxetine only once $\left(0.23 \pm 0.05, r^{2}=0.97\right)$. Saline, $n=6$ (17 slices); fluoxetine $24 h, n=6$

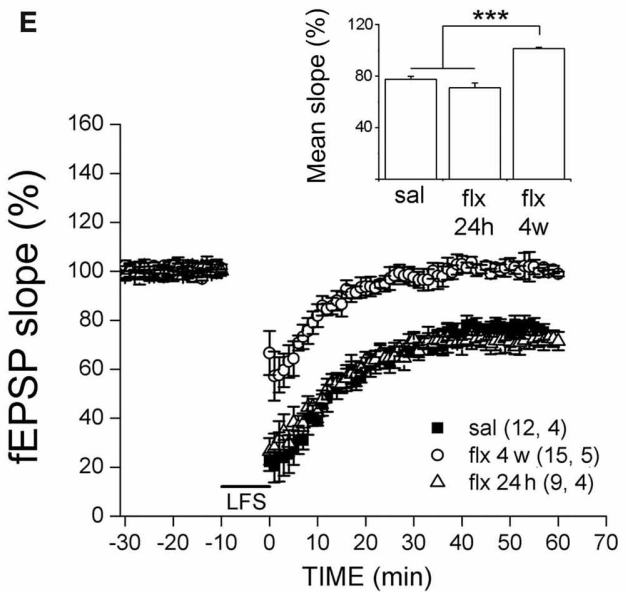

(14 slices); fluoxetine 4 weeks, $n=8$ (20 slices). (C) Representative traces of extracellular field recordings are shown before and after LTP (upper panels) or LTD (lower panels) induction. (D) Long-term potentiation (LTP) induced by theta burst stimulation (TBS) and (E) long-term depression (LTD) induced by low frequency stimulation (LFS) were blocked in hippocampal slices of rats treated for 4 weeks with fluoxetine. Bar graphs represent the mean \% change in fEPSP slopes compared to baseline, from 45 to 60 min after LTP (D inset) or LTD induction (E inset). LTP: sal, $n=4$ (14 slices); flx 4 weeks, $n=6$ (14 slices); flx 24 h, $n=6$ (12 slices). LTD: sal, $n=4$ (12 slices); flx 4 weeks, $n=5$ ( 15 slices); flx 24 h, $n=4$ (9 slices). Data from $\mathbf{D}$ and $\mathbf{E}$ were statistically evaluated by one-way ANOVA, followed by a Bonferroni post hoc test. ${ }^{* *} p<0.01,{ }^{* * *} p<0.001$. 
A

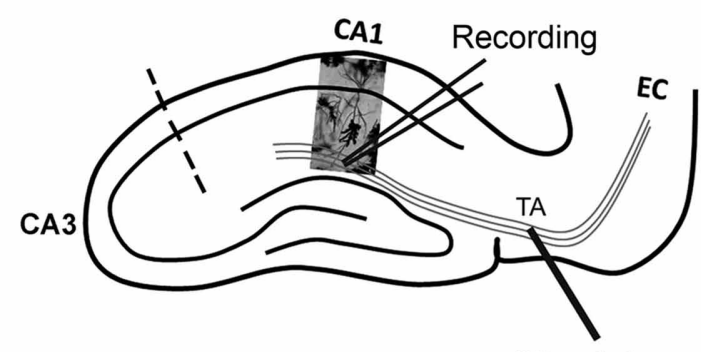

Stimulation

C

sal

flx $4 \mathrm{w}$
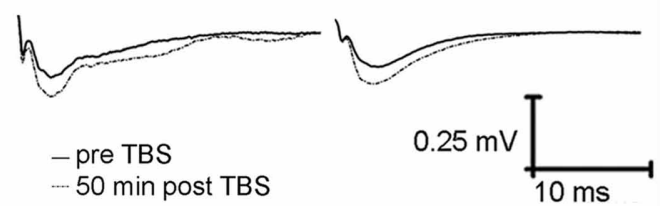

E

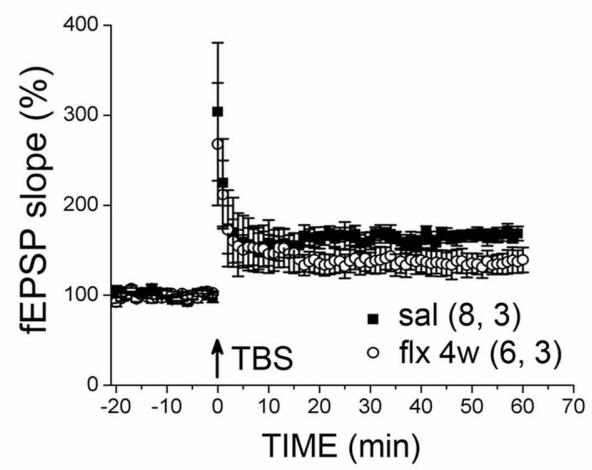

FIGURE 4 | Four weeks of fluoxetine administration does not affect synaptic plasticity at perforant pathway-CA1 synapses. Experiments were performed in slices from saline- (sal) and fluoxetine- (flx 4 weeks) treated rats. (A) The diagram shows the stimulating electrode inserted into the temporoammonic pathway (TA) and the recording electrode in the CA1 s.I.m. EC, entorhinal cortex. The dashed line indicates the place of the physical de-afferentation of Schaffer collateral inputs to CA1. (B) The fEPSP slopes vs. increasing presynaptic fiber volley (FV) amplitudes were plotted to analyze the input/output curves. No significant difference between salineand repetitive fluoxetine-treated rats was found after data were fit to a linear
B

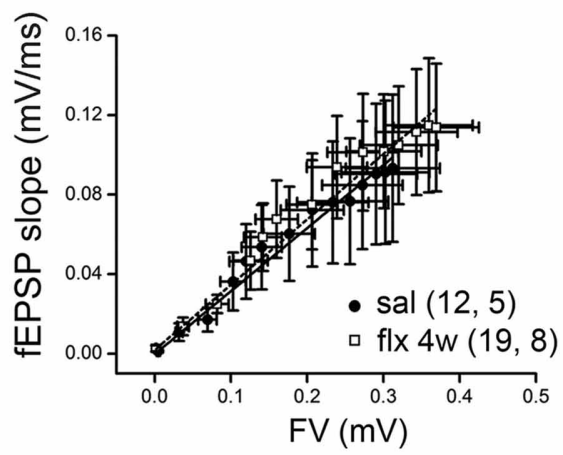

D

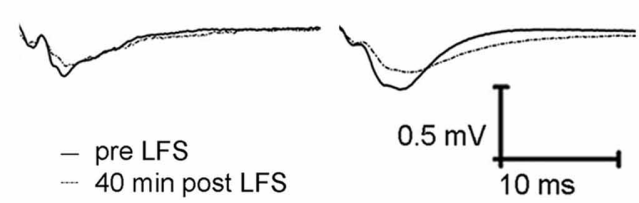

F

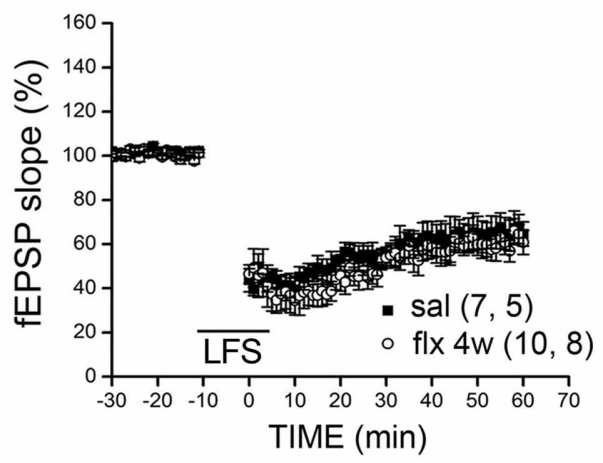

regression and compared using covariate analysis. Saline, $n=5$ (12 slices); fluoxetine 4 weeks, $n=8$ (19 slices). (C,D) Sample traces of extracellular field recordings are shown before and after LTP (E) or LTD (F) induction. (E) Long-term potentiation (LTP) induced by theta burst stimulation (TBS) were unaffected after perforant pathway stimulation. No significant difference was found when the mean fEPSP integrated between 45 and 60 min after LTP induction was compared ( $p=0.143$; unpaired $t$-test). LTP: sal, $n=3$ (8 slices); flx 4 weeks, $n=3$ (6 slices). (F) Similar LTD was also induced by low frequency stimulation (LFS) of the perforant path in slices from salineand fluoxetine-treated animals ( $p=0.519$; unpaired $t$-test).

in AMPA-R stoichiometry in the s.r. might contribute to the described effect. An increased GluA2 over GluA1 content in AMPA-Rs, associated with enhanced dendritic spine density was reported previously in the telencephalon by western blots of immunoprecipitated receptor subunits from postsynaptic densities and in isolated synaptosomes. In turn, immunohistochemistry and morphological analysis revealed that changes were restricted to some neocortical regions, while the hippocampus, with its well-defined cellular layers and dendritic sub-regions, was not analyzed (Ampuero et al., 2010). To now explore a functional implication of such molecular and morphological adaptations, we took advantage of the well-characterized activitydependent cellular plasticity paradigms in the hippocampal CA1 region. 

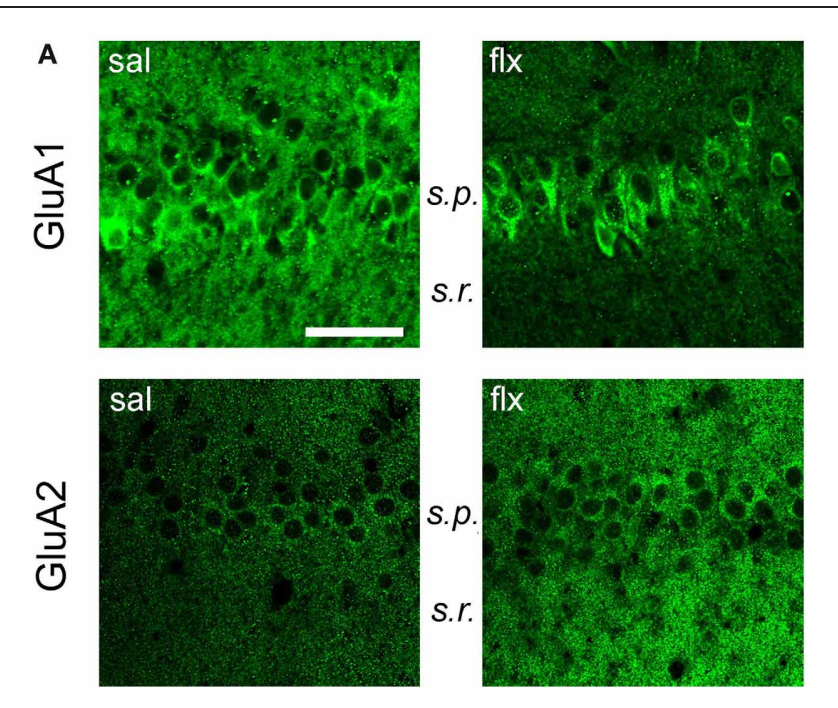

B
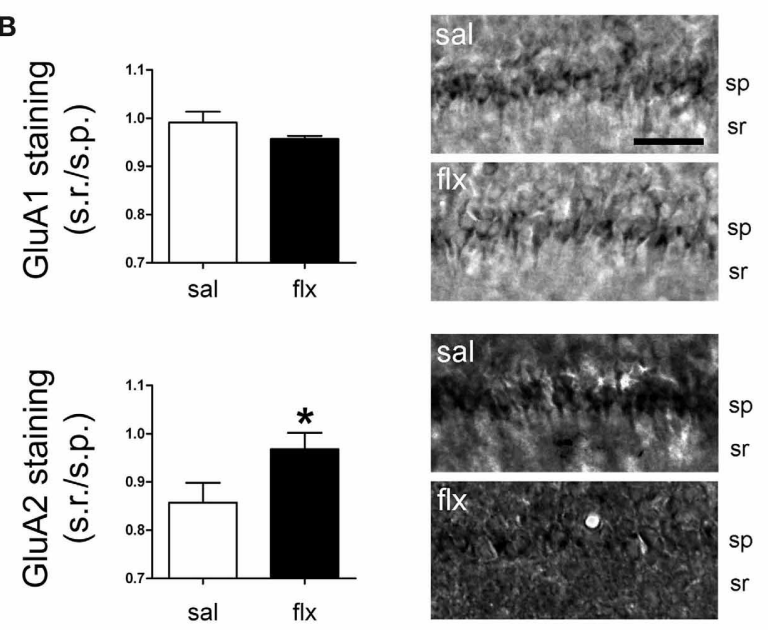

FIGURE 5 | GluA1 and GluA2 were detected in the CA1 region by immunofluorescence and immunohistochemical staining. (A)

Fluorescence images of GluA1 and GluA2 immunostainings reveal a change in the distribution of subunits between the cell soma (s.p.) and dendritic (s.r.) compartments. (B) Relative staining intensity (s.r./s.p.) of immunohistochemical GluA1 and GluA2 stainings revealed higher GluA2 intensity in the s.r. of fluoxetine-treated rats $\left(^{*} p<0.05, n=5-7\right.$, Student t-test). s.r., stratum radiatum; s.p., stratum pyramidale. Scale bars: $50 \mu \mathrm{m}$.

\section{HOMEOSTATIC SYNAPTIC ADAPTATIONS AT THE CA1 HIPPOCAMPAL SUBFIELD ARE POSSIBLY INDUCED BY LONG-TERM FLUOXETINE TREATMENT}

The CA1 hippocampal region is densely innervated by serotoninergic fibers originating in the dorsal raphe nuclei (Jacobs and Azmitia, 1992), which regulate excitability and synaptic transmission via activation of a large range of receptor subtypes. An enhanced serotonin-mediated synaptic response is caused by 5-HT7 and 5-HT4 receptors (Torres et al., 1995; Costa et al., 2011), while 5-HT1A and 5-HT1B activation results in hyperpolarization and, hence, decreased excitability (Andrade and Chaput, 1991; Mlinar et al., 2003). Interestingly, the integration of excitatory and inhibitory serotonin inputs resulted in global inhibition of CA1 neurons that could be observed either following activation of the raphe nuclei in vivo (Segal, 1975) or after local serotonin application (Otmakhova and Lisman, 2000; Otmakhova et al., 2005), supporting the idea of a homeostatic up-scaling induced by long-term elevation of serotonin levels (Turrigiano et al., 1998). Therefore, serotonin-mediated tonic inhibition of glutamatergic CA1 pyramidal neurons could trigger an adaptive homeostatic response leading to enhanced basal neurotransmission and dendritic spine remodeling (Turrigiano, 1999). However, how this remodeling can be performed in a differential manner along the dendritic tree is presently unknown. A differential serotoninergic innervation of s.l.m. dendrites compared to the s.r. dendrites as well as possible serotonin receptor subtype gradients might contribute to such effects (Moore and Halaris, 1975; Oleskevich and Descarries, 1990). Gradients of intrinsic membrane conductances and of glutamate receptors along the dendritic tree in the CA1 region will also influence post-synaptic responses and activity-dependent plasticity (Nolan et al., 2004; Nicholson et al., 2006; Camp, 2012). In addition, the mechanisms that contribute to plasticity are differentially expressed along both afferent pathways that contact CA1 apical dendrites: while an enhancement of pre-synaptic glutamate release contributes to perforant path-CA1 LTP, this does not occur at CA3-CA1 LTP (Ahmed and Siegelbaum, 2009), although both are NMDA-R dependent. A similar effect of fluoxetine on spine morphology in the CA1 s.r. had already been described (Hajszan et al., 2005), however, the CA1 s.l.m. was not analyzed nor inputspecific electrophysiological recordings were performed. The fact that LTP was unaffected in the direct perforant pathway input to the CA1 region, at least until $60 \mathrm{~min}$ after induction, favors the idea that the deficit in synaptic plasticity at CA3-CA1 synapses was associated to changes in postsynaptic spine morphology, i.e., that stronger and more "mature" synapses negatively affected further activity-dependent plasticity at CA3-CA1 synapses.

\section{PARTICIPATION OF AMPA-RS IN FLUOXETINE-INDUCED EFFECTS}

In agreement with a homeostatic-like synaptic re-organization induced by inhibitory-acting serotonin, synaptic scaling following the blockade of network activity is mediated by an accumulation of GluA2-containing AMPA-Rs (Gainey et al., 2009). In such a way, $\mathrm{Ca}^{2+}$ entry is abolished in AMPA-Rs containing solely GluA2 (Traynelis et al., 2010). Moreover, GluA2 deficient mice exhibited increased $\mathrm{Ca}^{2+}$ permeability and enhanced LTP (Jia et al., 1996). Therefore, the increase of GluA2 staining in dendrites is consistent with the data obtained with cobalt measurements assessing $\mathrm{Ca}^{2+}$ permeability. It had been shown that repetitive fluoxetine treatment increased the expression of AMPA-R subunits in the forebrain, including the prefrontal cortex and hippocampus (Ampuero et al., 2010; Barbon et al., 2011). However, the fact that GluA2 staining and $\mathrm{Ca}^{2+}$ permeability was increased and decreased, respectively, in the s.r. is in line with the change in fluoxetine-induced AMPA-R subunit composition reported to occur in isolated synaptic fractions derived from the whole forebrain (Ampuero et al., 2010). Thus, reduced AMPA-R dependent $\mathrm{Ca}^{2+}$ influx in CA1 dendrites could contribute to the impairment in activity-dependent plasticity. The participation of 

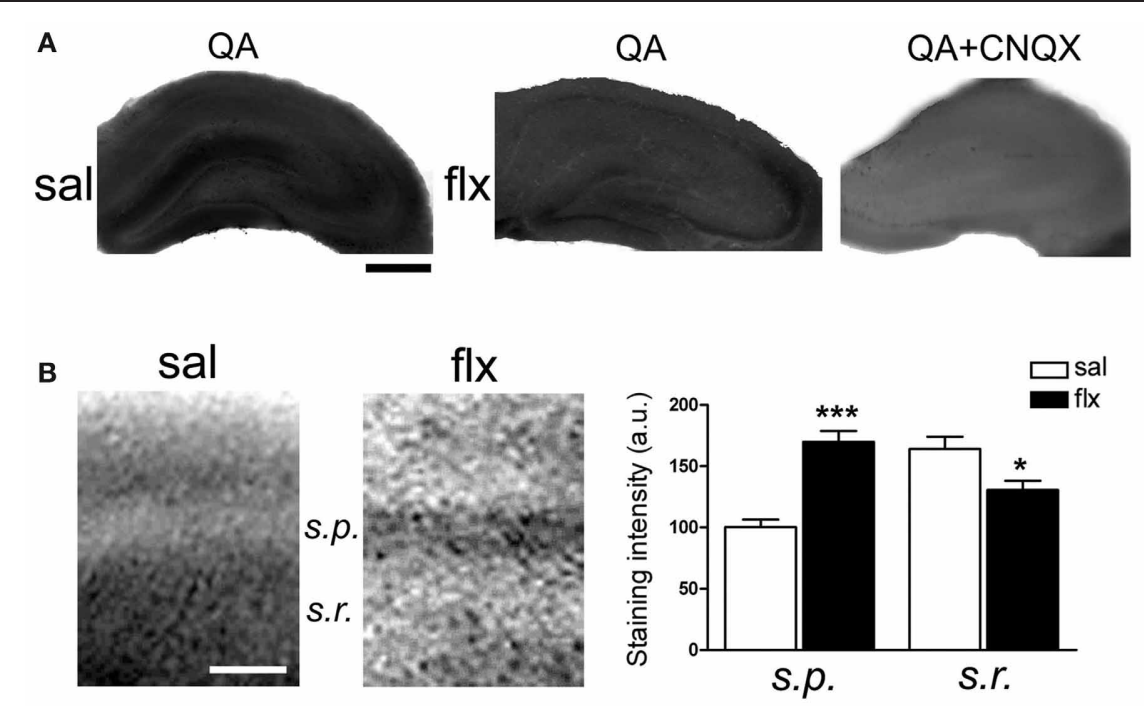

FIGURE 6 | Long-term fluoxetine administration decreased $\mathrm{Ca}^{2+}$-permeable AMPA-Rs in the CA1 stratum radiatum (s.r.). Hippocampal slices from saline- (sal) and fluoxetine- $(\mathrm{fl} x)$ treated rats were stimulated with $100 \mu \mathrm{M}$ quisqualic acid (QA) to detect $\mathrm{Co}^{2+}$ uptake. The AMPA-R blocker CNOX $(20 \mu \mathrm{M})$ was used as a negative control (QA+CNQX). (A) Hippocampal sections are shown in each experimental condition. Bar: $500 \mu \mathrm{m}$. (B) Increased magnification was used to quantify relative staining in the two CA1 subfields: stratum pyramidale (s.p.) and s.r. Bar: $50 \mu \mathrm{m}$. Bar graphs: the mean optical density was plotted. Data were statistically evaluated with the Mann-Whitney $U$-test, ${ }^{*} p<0.05$, *** $p<0.001 . \quad$ ( $n=9$ group). other $\mathrm{Ca}^{2+}$-permeable ion channels, e.g., NMDA-Rs and voltagesensitive $\mathrm{Ca}^{2+}$-channels, cannot be excluded. Interestingly, it has been shown that the latter can regulate $\mathrm{Ca}^{2+}$ influx into dendritic spines in a homeostatic manner (Yasuda et al., 2003). Moreover, along with a change in AMPA-R subunit composition, fluoxetine also induces a switch toward GluN2A-rich NMDA-Rs (Ampuero et al., 2010), which are characterized by a reduced $\mathrm{Ca}^{2+}$ influx when compared to GluN2B subunit-containing receptors.

The prevailing view regarding the participation of AMPA-R subunits in LTP and LTD establishes that GluA1 subunits become inserted or endocytosed to the synapse in an activity dependent manner while GluA2/GluA3 subunits traffic constitutively. Double GluA2/3 knockout animals continue to express LTP and LTD (Meng et al., 2003), while GluA1 availability and trafficking is required for early expression of LTP and LTD (Derkach et al., 2007). Recent findings indicate that LTP depends more importantly on the presence of an AMPA-R reserve pool than on specific subunits (Granger et al., 2013). Taken together, the effect of fluoxetine could be due to a deficiency in GluA1 subunit trafficking and/or membrane insertion leading to a relative lack of extra-synaptic AMPA-Rs.

\section{EFFECT OF FLUOXETINE ON PLASTICITY PARADIGMS}

Our study revealed that 28 days of fluoxetine impaired activitydependent plasticity that was associated with changes in spine morphology. This is in opposition to two previous studies which reported that fluoxetine restored developmental- or juvenile-like plasticity in the visual cortex or lateral amygdala, respectively, in adult rodents (Maya Vetencourt et al., 2008; Karpova et al., 2011). In the first study, Maya Vetencourt et al. used a similar treatment duration and doses, although the rat strain was different
(Maya Vetencourt et al., 2008). In the second study, Karpova et al. administered fluoxetine to juvenile mice (P42) at a 14-fold higher dose for 3 weeks (Karpova et al., 2011). Therefore, differences in the age of animals, treatment duration, examined brain area, as well in the strains of rats or rodent species used may critically influence the outcomes of the experiments. Especially differences in the density of serotoninergic innervation and in the expression of serotonin receptor subtypes might define the consequences of fluoxetine-induced serotonin elevation. Indeed, the apparent contradictory effect of repetitive fluoxetine on LTP (i.e., facilitator in the lateral amygdala but blocker in the CA s.r.) might be explained by the differential effect of serotonin in these regions. While serotonin activated excitatory principal neurons of the lateral amygdala by enhancing depolarization through $5-\mathrm{HT}_{2}$ receptors (Yamamoto et al., 2012), it activated inhibitory interneurons in the hippocampal CA1 subfield (Shen and Andrade, 1998) and acted on inhibitory receptors expressed by CA1 pyramidal neurons. In the visual cortex, reduced intra-cortical inhibition was associated with the effect of chronic fluoxetine treatment on restoration of LTP in the visual cortex (Maya Vetencourt et al., 2008). The role of the inhibitory tone at CA3-CA1 synapses was not tested in the present study.

Another study showed that repeated fluoxetine administration using a dose of $1 \mathrm{mg} / \mathrm{kg}$, close to the dose used by us, reduced LTP at perforant path-dentate gyrus synapses (Stewart and Reid, 2000). The idea that in the CA1 region serotonin inhibited LTP was discussed in a previous in vivo study, in which acute fluoxetine administration $(10 \mathrm{mg} / \mathrm{kg}$, i.p., $40 \mathrm{~min}$ prior to Schaffer collateral stimulation) increased serotonin levels, which, in turn, blocked CA1 LTP (Shakesby et al., 2002). This blocking effect could be ascribed to immediate elevation of serotonin, while a 
single fluoxetine administration, even at higher doses, should not lead to maintained high serotonin levels $24 \mathrm{~h}$ after the injection (Caccia et al., 1990). This suggested that the effect we observed after 4 weeks of administration, but measured 24 after the last dose, was a consequence of adaptive plastic changes that required repeated fluoxetine administration, and not to acute changes in serotonin. Consistent with our data, it was shown that repeated administration of methamphetamine, a drug that acts on central monoamine neurotransmission, including the serotonin system, enhanced basal neurotransmission and had a detrimental effect on CA3-CA1 synaptic plasticity (Swant et al., 2010).

The increased fEPSPs revealed in I/O curves in fluoxetinetreated animals could be due to direct effects of fluoxetine on glutamate receptors. However, fluoxetine has inhibitory effects on AMPA and NMDA receptors (Szasz et al., 2007; Kim et al., 2013) and therefore, decreased fEPSPs should be expected. In consequence, the most straightforward explanation is that larger spines are able to elicit larger post-synaptic responses. This could be mediated by several plasticity-related signals that are expressed following fluoxetine treatment, such as BDNF (Castren, 2005; Bath et al., 2012) or IGF-1 (Corvin et al., 2012), which in turn are able to stimulate glutamate receptor expression and receptor phosphorylation (Slack et al., 2004; First et al., 2011). A changed inhibition due to serotonin-induced re-arrangements of interneurons can also contribute to this phenomenon (Mendez et al., 2012).

The concept of meta-plasticity posits that synapses that have previously been potentiated are more likely to express LTD and less likely to express LTP, whereas the opposite applies if LTD has been previously induced (Bear, 2003). It is therefore difficult to reconcile that both plasticity paradigms are impaired under the

\section{REFERENCES}

Ahmed, M. S., and Siegelbaum, S. A. (2009). Recruitment of N-Type $\mathrm{Ca}(2+)$ channels during LTP enhances low release efficacy of hippocampal CA1 perforant path synapses. Neuron 63, 372-385.

Ampuero, E., Dagnino-Subiabre, A., Sandoval, R., Zepeda-Carreno, R., Sandoval, S., Viedma, A., et al. (2007). Status epilepticus induces region-specific changes in dendritic spines, dendritic length and $\operatorname{TrkB}$ protein content of rat brain cortex. Brain Res. 1150, 225-238.

Ampuero, E., Rubio, F. J., Falcon, R., Sandoval, M., Diaz-Veliz, G., Gonzalez, R. E., et al. (2010). Chronic fluoxetine treatment induces structural plasticity and selective changes in glutamate receptor subunits in the rat cerebral cortex. Neuroscience 169, 98-108.

Ampuero, E., Stehberg, J., Gonzalez, D., Besser, N., Ferrero, M., Diaz-Veliz, G., et al. (2013). Repetitive fluoxetine treatment affects long-term memories but not learning. Behav. Brain Res. 247, 92-100.
Andrade, R., and Chaput, Y. (1991). 5-Hydroxytryptamine4-like receptors mediate the slow excitatory response to serotonin in the rat hippocampus. J. Pharmacol. Exp. Ther. 257, 930-937.

Barbon, A., Caracciolo, L., Orlandi, C., Musazzi, L., Mallei, A., La Via, L., et al. (2011). Chronic antidepressant treatments induce a time-dependent up-regulation of AMPA receptor subunit protein levels. Neurochem. Int. 59, 896-905.

Bath, K. G., Jing, D. Q., Dincheva, I., Neeb, C. C., Pattwell, S. S., Chao, M. V., et al. (2012). BDNF Val66Met impairs fluoxetineinduced enhancement of adult hippocampus plasticity. Neuropsychopharmacology 37, 1297-1304.

Bear, M. F. (2003). Bidirectional synaptic plasticity: from theory to reality. Philos. Trans. R. Soc. Lond. B Biol. Sci. 358, 649-655.

Blier, P., Keller, M. B., Pollack, M. H., Thase, M. E., Zajecka, J. M., and Dunner, D. L. (2007). Preventing recurrent depression: long-term

used experimental conditions. If LTP is occluded due to a synaptic up-scaling at CA3-CA1 synapses, LTD should be enhanced, but not decreased, at these synapses. We therefore propose that $\mathrm{Ca}^{2+}$ influx pathways and/or $\mathrm{Ca}^{2+}$ changes in dendritic spines caused by intracellular release or changes in buffering capacity, might be altered thereby affecting both plasticity paradigms. Further experiments, using different stimulation protocols, increasing extracellular $\mathrm{Ca}^{2+}$ concentration or blocking inhibitory interneurons need to be performed to get insight into underlying mechanisms. However, it is clear that maintaining the stimulation conditions of the control group in fluoxetine-treated animals, both LTP and LTD are impaired. Similarly, a specific stimulation protocol and learning procedures can lead to occlusion of both LTP and LTD (Liang et al., 2002; Delvendahl et al., 2010), as we found in fluoxetine-treated animals.

In agreement with our findings, chronic escitalopram treatment inhibited CA3-CA1 LTP in healthy rats in a stress-resistant strain (Flinders Resistant Line rats, Karolinska Institutet). This phenomenon was attenuated after exposure to stress (Ryan et al., 2009), thereby confirming a distinct result in naïve subjects. Although the effect of fluoxetine described by us may be restricted to non-stressed or non-depressed subjects, we report that repetitive treatment impacts significantly glutamate neurotransmission and plasticity in the hippocampus.

\section{ACKNOWLEDGMENTS}

Funding for this study was provided by grants to Ursula Wyneken from Conicyt (Anillo ACT09_2006) and by Universidad de los Andes (MED-001-09) to Francisco J. Rubio. The authors thank for the critical review by Dr. Bruce Hope (NIDA, NIH). We also thank Ximena Orellana for her technical assistance.

treatment for major depressive disorder. J. Clin. Psychiatry 68, e06.

Caccia, S., Cappi, M., Fracasso, C., and Garattini, S. (1990). Influence of dose and route of administration on the kinetics of fluoxetine and its metabolite norfluoxetine in the rat. Psychopharmacology (Berl.) 100, 509-514.

Camp, A. J. (2012). Intrinsic neuronal excitability: a role in homeostasis and disease. Front. Neurol. 3:50. doi: 10.3389/fneur.2012.00050

Castren, E. (2005). Is mood chemistry? Nat. Rev. Neurosci. 6, 241-246.

Citri, A., and Malenka, R. C. (2008). Synaptic plasticity: multiple forms, functions, and mechanisms. Neuropsychopharmacology 33, 18-41.

Corvin, A. P., Molinos, I., Little, G., Donohoe, G., Gill, M., Morris, D. W., et al. (2012). Insulin-like growth factor 1 (IGF1) and its active peptide (1-3)IGF1 enhance the expression of synaptic markers in neuronal circuits through different cellular mechanisms. Neurosci. Lett. 520, 51-56.
Costa, L., Trovato, C., Musumeci, S. A., Catania, M. V., and Ciranna, L. (2011). 5-HT(1A) and 5-HT(7) receptors differently modulate AMPA receptor-mediated hippocampal synaptic transmission. Hippocampus 22, 790-801.

Delvendahl, I., Jung, N. H., Mainberger, F., Kuhnke, N. G., Cronjaeger, M., and Mall, V. (2010). Occlusion of bidirectional plasticity by preceding low-frequency stimulation in the human motor cortex. Clin. Neurophysiol. 121, 594-602.

Derkach, V. A., Oh, M. C., Guire, E. S., and Soderling, T. R. (2007) Regulatory mechanisms of AMPA receptors in synaptic plasticity. Nat. Rev. Neurosci. 8, 101-113.

First, M., Gil-Ad, I., Taler, M., Tarasenko, I., Novak, N., and Weizman, A. (2011). The effects of fluoxetine treatment in a chronic mild stress rat model on depression-related behavior, brain neurotrophins and ERK expression. J. Mol. Neurosci. 45, 246-255.

Gainey, M. A., Hurvitz-Wolff, J. R., Lambo, M. E., and Turrigiano, G. G. 
(2009). Synaptic scaling requires the GluR2 subunit of the AMPA receptor. J. Neurosci. 29, 6479-6489.

Granger, A. J., Shi, Y., Lu, W., Cerpas, M., and Nicoll, R. A. (2013). LTP requires a reserve pool of glutamate receptors independent of subunit type. Nature 493, 495-500.

Hajszan, T., Maclusky, N. J., and Leranth, C. (2005). Short-term treatment with the antidepressant fluoxetine triggers pyramidal dendritic spine synapse formation in rat hippocampus. Eur. J. Neurosci. 21, 1299-1303.

Harris, K. M., Jensen, F. E., and Tsao, B. (1992). Three-dimensional structure of dendritic spines and synapses in rat hippocampus (CA1) at postnatal day 15 and adult ages: implications for the maturation of synaptic physiology and longterm potentiation. J. Neurosci. 12, 2685-2705.

He, K., Lee, A., Song, L., Kanold, P. O., and Lee, H. K. (2011). AMPA receptor subunit GluR1 (GluA1) serine845 site is involved in synaptic depression but not in spine shrinkage associated with chemical longterm depression. J. Neurophysiol. 105, 1897-1907.

Isaac, J. T., Ashby, M. C., and McBain, C. J. (2007). The role of the GluR2 subunit in AMPA receptor function and synaptic plasticity. Neuron 54, 859-871.

Jacobs, B. L., and Azmitia, E. C. (1992). Structure and function of the brain serotonin system. Physiol. Rev. 72, 165-229.

Jia, Z., Agopyan, N., Miu, P., Xiong, Z., Henderson, J., Gerlai, R., et al. (1996). Enhanced LTP in mice deficient in the AMPA receptor GluR2. Neuron 17, 945-956.

Karpova, N. N., Pickenhagen, A., Lindholm, J., Tiraboschi, E., Kulesskaya, N., Agustsdottir, A., et al. (2011). Fear erasure in mice requires synergy between antidepressant drugs and extinction training. Science 334, 1731-1734.

Kim, H. J., Kim, T. H., Choi, S. J., Hong, Y. J., Yang, J. S., Sung, K. W., et al. (2013). Fluoxetine suppresses synaptically induced $[\mathrm{Ca}(2)(+)] \mathrm{i}$ spikes and excitotoxicity in cultured rat hippocampal neurons. Brain Res. 1490, 23-34.

Liang, P. I., Yang, H. W., Lin, Y. W., Yen, C. D., and Min, M. Y. (2002). The effect of prior prolonged low frequency stimulation on the further synaptic plasticity at hippocampal CA1 synapses. Chin. J. Physiol. 45, 63-67.

Maya Vetencourt, J. F., Sale, A., Viegi, A., Baroncelli, L., De Pasquale, R.,
O'Leary, O. F., et al. (2008). The antidepressant fluoxetine restores plasticity in the adult visual cortex. Science 320, 385-388.

Maya-Vetencourt, J. F., Tiraboschi, E., Greco, D., Restani, L., Cerri, C., Auvinen, P., et al. (2012). Experience-dependent expression of NPAS4 regulates plasticity in adult visual cortex. J. Physiol. 590, 4777-4787.

Maya Vetencourt, J. F., Tiraboschi, E., Spolidoro, M., Castren, E., and Maffei, L. (2011). Serotonin triggers a transient epigenetic mechanism that reinstates adult visual cortex plasticity in rats. Eur. J. Neurosci. 33, 49-57.

Medvedev, N. I., Rodríguez-Arellano, J. J., Popov, V. I., Davies, H. A., Tigaret, C. M., Schoepfer, R., et al. (2008). The glutamate receptor 2 subunit controls post-synaptic density complexity and spine shape in the dentate gyrus. Eur. J. Neurosci. 27, 315-325.

Megias, M., Emri, Z., Freund, T. F., and Gulyas, A. I. (2001). Total number and distribution of inhibitory and excitatory synapses on hippocampal CA1 pyramidal cells. Neuroscience 102, 527-540.

Mendez, P., Pazienti, A., Szabo, G., and Bacci, A. (2012). Direct alteration of a specific inhibitory circuit of the hippocampus by antidepressants. J. Neurosci. 32, 16616-16628.

Meng, Y., Zhang, Y., and Jia, Z. (2003). Synaptic transmission and plasticity in the absence of AMPA glutamate receptor GluR2 and GluR3. Neuron 39, 163-176.

Mlinar, B., Falsini, C., and Corradetti, R. (2003). Pharmacological characterization of 5-HT(1B) receptor-mediated inhibition of local excitatory synaptic transmission in the CAl region of rat hippocampus. Br. J. Pharmacol. 138, 71-80.

Moore, R. Y., and Halaris, A. E. (1975). Hippocampal innervation by serotonin neurons of the midbrain raphe in the rat. J. Comp. Neurol. 164, 171-183.

Nicholson, D. A., Trana, R., Katz, Y., Kath, W. L., Spruston, N., and Geinisman, Y. (2006). Distancedependent differences in synapse number and AMPA receptor expression in hippocampal CAl pyramidal neurons. Neuron 50, 431-442.

Nolan, M. F., Malleret, G., Dudman, J. T., Buhl, D. L., Santoro, B., Gibbs, E., et al. (2004). A behavioral role for dendritic integration: HCN1 channels constrain spatial memory and plasticity at inputs to distal dendrites of CA1 pyramidal neurons. Cell 119, 719-732.

Oleskevich, S., and Descarries, L. (1990). Quantified distribution of the serotonin innervation in adult rat hippocampus. Neuroscience 34, 19-33.

Olmos, C., Sandoval, R., Rozas, C., Navarro, S., Wyneken, U., Zeise, M., et al. (2009). Effect of short-term exposure to dichlorvos on synaptic plasticity of rat hippocampal slices: involvement of acylpeptide hydrolase and alpha(7) nicotinic receptors. Toxicol. Appl. Pharmacol. 238, 37-46.

Osswald, I. K., Galan, A., and Bowie, D. (2007). Light triggers expression of philanthotoxin-insensitive $\mathrm{Ca} 2+$ permeable AMPA receptors in the developing rat retina. J. Physiol. 582, 95-111.

Otmakhova, N. A., Lewey, J., Asrican, B., and Lisman, J. E. (2005). Inhibition of perforant path input to the CAl region by serotonin and noradrenaline. J. Neurophysiol. 94, 1413-1422.

Otmakhova, N. A., and Lisman, J. E. (2000). Dopamine, serotonin, and noradrenaline strongly inhibit the direct perforant path-CA1 synaptic input, but have little effect on the Schaffer collateral input. Ann. N.Y. Acad. Sci. 911, 462-464.

Pittenger, C., and Duman, R. S. (2008). Stress, depression, and neuroplasticity: a convergence of mechanisms. Neuropsychopharmacology 33 , 88-109.

Pyapali, G. K., Sik, A., Penttonen, M., Buzsaki, G., and Turner, D. A. (1998). Dendritic properties of hippocampal CA1 pyramidal neurons in the rat: intracellular staining in vivo and in vitro. J. Comp. Neurol. 391, 335-352.

Remondes, M., and Schuman, E. M. (2002). Direct cortical input modulates plasticity and spiking in CA1 pyramidal neurons. Nature 416, 736-740.

Ryan, B., Musazzi, L., Mallei, A., Tardito, D., Gruber, S. H., El Khoury, A., et al. (2009). Remodelling by early-life stress of NMDA receptor-dependent synaptic plasticity in a gene-environment rat model of depression. Int. J. Neuropsychopharmacol. 12, 553-559.

Sanacora, G., Zarate, C. A., Krystal, J. H., and Manji, H. K. (2008). Targeting the glutamatergic system to develop novel, improved therapeutics for mood disorders. Nat. Rev. Drug Discov. 7, 426-437.
Schatzberg, A. F. (2000). New indications for antidepressants. J. Clin. Psychiatry 61(Suppl. 11), 9-17.

Segal, M. (1975). Physiological and pharmacological evidence for a serotonergic projection to the hippocampus. Brain Res. 94, 115-131.

Segal, M. (2005). Dendritic spines and long-term plasticity. Nat. Rev. Neurosci. 6, 277-284.

Shakesby, A. C., Anwyl, R., and Rowan, M. J. (2002). Overcoming the effects of stress on synaptic plasticity in the intact hippocampus: rapid actions of serotonergic and antidepressant agents. J. Neurosci. 22, 3638-3644.

Shen, R. Y., and Andrade, R. (1998). 5-Hydroxytryptamine2 receptor facilitates GABAergic neurotransmission in rat hippocampus. J. Pharmacol. Exp. Ther. 285, 805-812.

Slack, S. E., Pezet, S., McMahon, S. B., Thompson, S. W., and Malcangio, M. (2004). Brain-derived neurotrophic factor induces NMDA receptor subunit one phosphorylation via ERK and PKC in the rat spinal cord. Eur. J. Neurosci. 20, 1769-1778.

Spruston, N. (2008). Pyramidal neurons: dendritic structure and synaptic integration. Nat. Rev. Neurosci. 9, 206-221.

Steward, O. (1976). Topographic organization of the projections from the entorhinal area to the hippocampal formation of the rat. J. Comp. Neurol. 167, 285-314.

Stewart, C. A., and Reid, I. C. (2000). Repeated ECS and fluoxetine administration have equivalent effects on hippocampal synaptic plasticity. Psychopharmacology (Berl.) 148, 217-223.

Swant, J., Chirwa, S., Stanwood, G., and Khoshbouei, H. (2010). Methamphetamine reduces LTP and increases baseline synaptic transmission in the CA1 region of mouse hippocampus. PLoS ONE 5:e11382. doi: 10.1371/journal.pone.0011382

Szasz, B. K., Mike, A., Karoly, R., Gerevich, Z., Illes, P., Vizi, E. S., et al. (2007). Direct inhibitory effect of fluoxetine on N-methylD-aspartate receptors in the central nervous system. Biol. Psychiatry 62, 1303-1309.

Torres, G. E., Chaput, Y., and Andrade, R. (1995). Cyclic AMP and protein kinase A mediate 5hydroxytryptamine type 4 receptor regulation of calcium-activated potassium current in adult hippocampal neurons. Mol. Pharmacol. 47, 191-197. 
Traynelis, S. F., Wollmuth, L. P., McBain, C. J., Menniti, F. S., Vance, K. M., Ogden, K. K., et al. (2010). Glutamate receptor ion channels: structure, regulation, and function. Pharmacol. Rev. 62, 405-496.

Turrigiano, G. G. (1999). Homeostatic plasticity in neuronal networks: the more things change, the more they stay the same. Trends Neurosci. 22, 221-227.

Turrigiano, G. G., Leslie, K. R., Desai, N. S., Rutherford, L. C., and Nelson, S. B. (1998). Activity-dependent scaling of quantal amplitude in neocortical neurons. Nature 391, 892-896.
Wang, Y., Neumann, M., Hansen, K., Hong, S. M., Kim, S., NobleHaeusslein, L. J., et al. (2011). Fluoxetine increases hippocampal neurogenesis and induces epigenetic factors but does not improve functional recovery after traumatic brain injury. J. Neurotrauma 28, 259-268.

Yamamoto, R., Ueta, Y., Sugai, T., and Kato, N. (2012). A serotonergic discrimination favoring synaptic inputs that accompany robust spike firing in lateral amygdala neurons. Neuroscience 220, 119-130.

Yasuda, R., Sabatini, B. L., and Svoboda, K. (2003). Plasticity of calcium channels in dendritic spines. Nat. Neurosci. 6, 948-955.

Conflict of Interest Statement: The authors declare that the research was conducted in the absence of any commercial or financial relationships that could be construed as a potential conflict of interest.

Received: 07 February 2013; accepted: 20 April 2013; published online: 09 May 2013.

Citation: Rubio FJ, Ampuero E, Sandoval $R$, Toledo J, Pancetti F and Wyneken U
(2013) Long-term fluoxetine treatment induces input-specific LTP and LTD impairment and structural plasticity in the CA1 hippocampal subfield. Front. Cell. Neurosci. 7:66. doi: 10.3389/fncel. 2013.00066

Copyright (C) 2013 Rubio, Ampuero, Sandoval, Toledo, Pancetti and Wyneken. This is an open-access article distributed under the terms of the Creative Commons Attribution License, which permits use, distribution and reproduction in other forums, provided the original authors and source are credited and subject to any copyright notices concerning any third-party graphics etc. 